\title{
Research on Influence of the Athletic Dance on the College Students’ Health
}

\author{
Guan Yi, Liu Fei \\ Sport and Art Department, Chengde Petroleum College, Chengde China
}

\begin{abstract}
Sports dance is a dance, music, clothing, grace and beauty in one elegant sport, sports, art, which spans three in the field of education, one item has the aesthetic value and entertainment value high comprehensive art. Sports dance is a very popular sport, has certain effect on the prevention and treatment of certain diseases. Therefore, sports dance has positive theoretical value and practical significance to improve the health level of College students. Paper gives the analysis of effects of sports dance on College students. Research shows that, through analysis and comparison, observation and physiology, if some people often and for a long period of time to participate in sports dance, so it can reduce human blood viscosity, improve fat metabolism, increase the serum level and lower serum density will be significantly improved.
\end{abstract}

Index Terms - sports dance, physical and mental health, College Students

\section{Introduction}

Through the observation and study of the year, we found that the mass sports dance in improving public health especially college students' health has played an important role. Sports dance can adjust these people's mind and body; we did some physiological analysis, the health effects of college students to the main processing of sports dance, especially on serum protein and blood density.

\section{Research Objectives and Methods}

A. The target

The experimental objects were divided into two groups: one group is experiment group, another group was control group. The experimental group is composed of personnel from 200 college students, they all participate in the sports dance and the average age is 20.35 years old. The members of the control group consisted of 200 patients with the same condition, but not in any physical exercise or activity of college students, their average age was21.12 years old.

\section{B. The method}

1) Serum five quota test: Using 721 spectrophotometer, taken from the morning fasting venous blood test for the 3 fat
(TC) and serum total cholesterol (T-ch), lipoprotein cholesterol high definition (hdI-ch), low density lipoprotein cholesterol in very

Low densities (DL-ch), lipoprotein cholesterol (VLDL-ch) and serum triglyceride (TC).

2)Blood circulation change measurement: Measurements include red blood cell drop rate, erythrocyte aggregation and the degree of density of blood.

Data processing. Blood flow detection system is used to test the blood flow changes, so as to find out the various data needed for computer processing, each number represents the average Sigma, the "T" test, some differences can test out.

\section{Conclusions}

(a) Table 1 shows the effect of sports dance on college students, serum protein, some changes that often take part in sports dance people from table 1 reflected, these changes can be seen: the level of HDL-ch in blood increased, serum TG and TC level increased slightly. Statistically significant differences between the two sets of data.

Table 1 Effect of sports dance on serum protein of college students $(x+s)$

\begin{tabular}{|c|c|c|c|c|}
\hline \multirow{2}{*}{} & \multicolumn{2}{|c|}{ The test set } & \multicolumn{2}{c|}{ Matching control } \\
\cline { 2 - 5 } & Before training & After training & Before training & After training \\
\hline T-ch & $194.13 \pm 30.56$ & $193.34 \pm 31.62$ & $195.25 \pm 32.18$ & $194.02 \pm 32.69$ \\
\hline HDL-ch & $56.16 \pm 9.49$ & $63.97 \pm 10.07$ & $56.02 \pm 10.38$ & $56.31 \pm 9.65$ \\
\hline LDL-ch & $115.48 \pm 12.61$ & $101.36 \pm 13.25$ & $112.85 \pm 13.42$ & $111.90 \pm 13.35$ \\
\hline TG & $137.93 \pm 22.18$ & $115.69 \pm 20.45$ & $133.25 \pm 23.82$ & $131.83 \pm 23.02$ \\
\hline
\end{tabular}

(b) From the experimental group can be found in some of the experimental group: change the blood circulation of the quota was better than the control group (Table 2). As shown in Figure 2: aggregation, in the red cell red blood cell drop rate, blood viscosity and blood reduced degree of index is very obvious. At the same time with statistical significance between the two groups $(\mathrm{P}<0.5)$ data.

Table 2 Effect of sports dance on college students of blood circulation

\begin{tabular}{|c|c|c|c|c|}
\hline & \multicolumn{2}{|c|}{ The test set } & \multicolumn{2}{c|}{ Matching control } \\
\cline { 2 - 5 } & Before training & After training & Before training & After training \\
\hline Red blood cell & $45.85 \pm 3.15$ & $44.0 \pm 3.64$ & $44.05 \pm 30.68$ & $43.93 \pm 3.92$ \\
\hline Erythrocyte sedimentation rate $(\mathrm{mn} / \mathrm{h})$ & $1.76 \pm 0.15$ & $1.75 \pm 0.16$ & $1.74 \pm 0.15$ & $1.75 \pm 0.16$ \\
\hline Collagen of blood & $43.85 \pm 3.15$ & $42.0 \pm 3.64$ & $43.05 \pm 30.68$ & $42.93 \pm 3.92$ \\
\hline All the blood of the collagen & $5.49 \pm 0.47$ & $5.21 \pm 0.48$ & $5.42 \pm 0.49$ & $5.34 \pm 0.44$ \\
\hline Reconstituted collagen degree & $9.86 \pm 1.05$ & $9.33 \pm 1.12$ & $9.76 \pm 1.18$ & $9.83 \pm 1.20$ \\
\hline The number of blood cells (Thousands $/ \mathrm{mn})$ & $491.05 \pm 46.28$ & $488.52 \pm 49.05$ & $497.05 \pm 46.28$ & $495.25 \pm 49.05$ \\
\hline
\end{tabular}




\section{Analysis}

\section{A. Effect of serum protein sports dance on the}

After 12 months of sports dance training, the experimental group in the internal body in particular has changed dramatically in the five serum quotas, while there is significant difference before and after the experiment. Compared with the control group, the difference has statistical significance $\quad(\mathrm{P}<0.05)$ Generally speaking, some medium-sized aerobics can activate the muscle and fatty acid, cholesterol and phospholipids into high density protein, resulting in serum cholesterol (HDL-CH) concentration is more and more strong, all this causes blood vessels to cholesterol in the liver metastasis and digestion. At the same time, long-term exercise can stop the cholesterol (VLDL-ch) in the liver of the reengineering. Leave on liver cholesterol transfer, VLDL-ch after digestion can be changed to LDL-ch. Therefore, changes of serum VLDL-ch and LDL-ch in two aspects, so that the blood cholesterol into mobile, clean up, prevent such as arteriosclerosis, cardiovascular system diseases and diseases of cerebral hemorrhage.

\section{B. Effect of sports dance on blood circulation}

Along with the growth of the age, their blood becomes dense, aggregation and concentrated, clinically known as blood high density, high cholesterol (VHS). This may lead to such as hypertension, coronary heart disease, coronary arteriosclerosis and thrombosis. From a medical point of view, the blood density may, to some extent, reflects the quality of blood transmission, because of age, cardiovascular function become weak, therefore, the blood concentration decreased for the people who might have good reconstruction function. This situation can also slow the decay trend growth of tissue cells with age. The blood concentration of experimental group staff participates in the regular sports dance was lower than the control group, which proves that often participate in sports dance can make the blood concentration in the normal state. At the same time, the blood concentration and erythrocyte aggregation is closely related to the higher concentration, blood, red blood cell aggregation will be more strong, erythrocyte aggregation affects the amount of blood circulation, when the blood concentration of $0.47-0.53$, the blood flow amount will be the $46.0 \mathrm{ml} / 100 \mathrm{~g}$, when the blood concentration of $0.36-0.46$, the blood flow amount will be $65.0 \mathrm{ml} / 100 \mathrm{~g}$. This shows that the accumulation of blood volume, blood flow is lower, the higher. This proof, long-term and regular sports dance training can improve the blood circulation, and provide enough blood to the head

Low accumulation of red blood cells, normal to maintain the surface charge of good on red blood cell, in order to avoid agglomeration of blood is very good. Aggregation of red blood cells, the experimental group and the control group were significantly different (Table 2), suggesting that the regular sports dance helps to improve and maintain the normal red blood cell surface density, these improvements can reduce the blood concentration, such as hypertension, coronary heart disease, arteriosclerosis and thrombosis and other diseases are effectively prevention.

C. The sports dance physical and psychological reasons.

Psychology is the action of the human brain, the mental health development, must take healthy body, especially the nervous system and brain healthy development material base. Physical exercise can promote the body's normal, healthy development; provide a solid material foundation for the development of psychology. This is the important condition of psychological development. Sports dance plays an active role in strengthening college students' health, here provides some of the characteristics of sport dance, show the reasons of their physiological and psychological in the following three aspects:

Dance in practice of elegant feeling. Sports dance music is full of lively rhythm and beautiful scene, students followed these music which makes them good condition in the sense of elegance, and these can improve heart function.

Overall motion. In the dance movements require dancers straighten chest, straight waist, tight hip, knee and shoulder to relax down, these can strengthen the chest, waist, hip, leg, and shoulder strength, prevent bending the body, which makes the human nervous system, respiratory system, digestive system and circulation system to normal operation.

Get rid of loneliness and casting temperament. College students with the increase of age and social work role change, they experience the loss of a series of, must adjust the role, in order to adapt to the new environment. Often participate in sports dance so they gathered together, to stimulate people to make new friends. Especially those busy in the heavy learning of college students, the lost and alone can lead to disease. The sports dance practice, these college students life rich, their troubles also eliminated, memory and judgment are improved, so the students have a full state of mind, full of hope for the future of life.

\section{References}

[1] Zhang Qu. Sports dance club in the quality education of university students in Shanxi higher school. Journal of social science. 2011 (01)

[2] Malian. Dance education in University on promoting. China Adult Education College Students' quality education. 2011 (02)

[3] Liu Wei. Dance sport to improve the analysis of. Science and technology information of the comprehensive quality of college students. 2011 (15)

[4] Li Chen. Analysis on how to implement quality education. Journal of Southwest Agricultural University in the Sports Dance Education University (SOCIAL SCIENCE EDITION). 2012 (01)

[5] Huang Yan. Influence of. Science and technology information of sports dance on College Students' overall quality. 2012 (02)

[6] Dai Labuan, stone lamp. College dance education to improve the overall quality of students the significance of. News universe (semimonthly) 2010 (05)

[7] Liu Hue. Dance sports aesthetic characteristics of. Science and Technology Innovation Herald, 2011 (08)

[8] Nye Jun, Sun Dishing. I see the sports dance. Anhui sports science and technology. 1995 (01)

[9] Zhang Joshing, Fang Mingle. Of Sandshoe fighters. Journal of Changzhou Teachers College, 2002 (05)

[10] Chen Shang. Study. Chinese adult education of sports dance music and aesthetics in 2004 (06)

[11] Tang Haying, Zhang Youngling. Analysis of college sports dance training of student's comprehensive quality and the role of the. Chinese education review. 2008(05) 